\title{
Projeto TEJA - Tecnologia Educacional para Jovens e Adultos: Enfrentando o Fracasso Escolar
}

Pesquisadores: Carmen Lúcia Guimarães de Mattos (coordenadora) Maria Lúcia Araújo Brandão Instituição: Universidade

Federal Fluminense (UFF) Fonte financiadora: Fundação de Amparo à Pesquisa do Rio de Janeiro

(FAPERJ)

\section{Introdução}

Durante a última década, a tecnologia eletrônica e, especialmente, os computadores tornaram-se importantes instrumentos pedagógicos. Essas tecnologias oferecem oportunidades especiais de suporte e expansão dos processos de ensino- aprendizagem em geral e, em particular, na alfabetização de jovens e adultos.

Com a crescente utilização de equipamentos eletrônicos (videogames, computadores, terminais bancários etc.) e com uma variedade de opções de programas (softwares), os educadores estão procurando uma integração efetiva dessas tecnologias 
com os mais diversos programas educacionais e atividades curriculares. E a tecnologia compondo a nova cultura pedagógica.

O Brasil, embora ainda pouco expressivo no contexto internacional em relação ao uso da alta tecnologia (computadores), não pode deixar de estar em sintonia com a modernidade e de acompanhar esse processo de mudança das relações sócio-educacionais, mediadas pela tecnologia, sob o risco de se distanciar cada vez mais do processo de desenvolvimento sóciocultural no contexto internacional.

\section{O Projeto}

O Projeto TEJA - Tecnologia Educacional para Jovens e Adultos: enfrentando o fracasso escolar caracteriza-se como um projeto integrado de ensino, pesquisa e extensão. Visa promovera alfabetização "funcional" de jovens e adultos e a formação profissional de alunos e pesquisadores, constituindo-se ainda um projeto-piloto para a criação de um centro de pesquisa em tecnologia educacional, que integre os múltiplos projetos nessa área.

Enquanto ensino o projeto atenderá alunos com alto risco de fracasso escolar e alunos já excluídos do processo de escolarização, que aguardam ansiosamente o reencontro com o conhecimento acadêmico formal (população de jovens e adultos), visando ao desenvolvimento da habilidade de utilização da linguagem relacionada ao processo de alfabetização chamada "funcional" (Street, 1984, p.243), mediante a utilização de computadores.

O conceito de alfabetização funcional inclui o desenvolvimento das habilidades de compreensão das várias formas de escrita de textos impressos, das habilidades de pensar criticamente, de raciocinar logicamente, de resolver problemas e de tomar decisões. Isto é de vital importância para a população de jovens e adultos, especialmente para aqueles que fracassaram na escola.

Enquanto pesquisa e extensão o projeto terá como foco de análise a utilização da alta tecnologia (computadores) na aquisição da alfabetização funcional e no desen- 
volvimento da linguagem escrita impressa e de outras formas de aprendizagem e habilidades. $\mathrm{O}$ treinamento de professores, alunos universitários e pessoas comuns da comunidade local que desejarem trabalhar como tutores nos centros de tecnologia educacional são parte da função da extensão, assim como também a contribuição oferecida pelos dados acessados para as futuras tomadas de decisão dos professores em sua ação pedagógica.

Enquanto projeto-piloto para a criação de um centro de tecnologia que funcione como um laboratório de pesquisa, o Projeto TEJA congregará universidades, através de equipes responsáveis pelo seu desenvolvimento, acompanhamento e avaliação nos centros de tecnologia educacional para jovens e adultos.

As universidades filiadas ao projeto deverão ser aquelas que atuem de forma ativa na rede pública de ensino, demonstrando excelência em relação ao desenvolvimento de projetos de pesquisa e extensão na área de educação; deverão desempenhar um papel de formadoras de profissionais para lidar com os diversos grupos sociais que necessitam de orientação para solucionar os problemas que se colocam em face da diversidade humana; deverão ainda atender às necessidades dos participantes quanto ao seu desenvolvimento educacional, além de criar novos conhecimentos sobre o desenvolvimento da escrita e da leitura para alunos excluídos do sistema educacional formal.

\section{Abordagem metodológica}

A linha mestra do projeto é a abordagem etnográfica crítica da escola, caracterizada mais especificamente por seu caráter colaborativo, isto é, pela colaboração entre pesquisadores e participantes (professor-aluno, tutor-aluno, pesquisador-participante).

A perspectiva etnográfica, num sentido amplo, caracteriza-se por analisar holística, interacional e dialeticamente a cultura; considera que os atores sociais têm participação ativa como agências humanas transformadoras das contradições sociais; revela a "caixa preta" do 
processo de escolarização, desvelando a natureza das interações sociais cotidianas.

Nesta abordagem qualitativa de pesquisa, a coleta e a análise dos dados dar-se-ão a partir do contexto natural, pelo contato direto entre o pesquisador e os participantes, por um período considerável de tempo. Assim, a etnografia crítica da sala de aula, como uma abordagem mais recente em pesquisa educacional, desenvolve-se a partir de um processo de mútuo comprometimento e colaboração entre pesquisadores e pesquisados, criando uma verdadeira relação de cumplicidade e credibilidade entre eles.

Muitas vezes o cotidiano torna-se invisível para os atores sociais nele envolvidos, seja pela "naturalidade" das ações rotineiras, seja pelas contradições existentes nas interações sociais que nelas se manifestam. Para tornarmos menos invisíveis estas relações, faz-se necessária uma investigação a partir do ponto de vista dos próprios atores sociais, para que eles possam entender melhor os processos de mudança ocorridos no seu cotidiano e para que os pesquisadores possam fazer sentido sobre a natureza do processo de mudança enquanto participantes externos a ele. Acreditamos que somente por meio dessas condições será possível validar os dados qualitativos que pudermos acessar, dando uma nova dimensão à pesquisa social da escola e das relações professor-aluno, procurando precisar um pouco melhor a natureza psicossocial dessa relação.

Serão utilizadas, ainda, técnicas e teorias da antropologia cultural e social, da sociolingüística e da etnometodologia é recursos da microanalise do comportamento verbal e não- verbal quanto aos padrões de organização social e cultural da interação face a face. Nesta direção integraremos observação participante e análise detalhada de gravações em áudio e videoteipes de atendimentos a alunos nos centros de tecnologia educacional, assim como outros instrumentos que se fizerem necessários para acessar dados que respondam às questões da pesquisa.

Meta e ações

Meta:

Criar centros de tecnologia educa- 
cional para funcionarem como para a aprendizagem, especialmente laboratórios de ensino e pesquisa no desenvolvimento das habilidades sobre dificuldades educacionais e sua que envolvem a linguagem escrita. superação, utilizando computadores. Além do interesse espontâneo que

Ações:

1. Adquirir $\mathrm{o}$ equipamento necessário.

2. Implantar centros de tecnologia educacional para jovens e adultos nos municípios que os desejarem.

3. Treinar tutores para a atuação nesses centros de tecnologia educacional.

4. Pesquisar a utilização da alta tecnologia na promoção da alfabetização funcional e de outras formas de aprendizagem e habilidades.

5. Desenvolver, acompanhar e avaliar o programa de alfabetização funcional nos centros de tecnologia educacional para jovens e adultos.

O computador como instrumento pedagógico

Em plena era da tecnologia acreditamos que os jovens e adultos podem encontrar no uso do computador um fator bastante motivador os jovens e adultos demonstram, há um clima produtivo, pois os alunos interagem com os professores, e suas dificuldades são trabalhadas individualmente, sem o comprometimento em termos de julgamentos pessoais do tutor. $\mathrm{O}$ processo instrucional mediado pelo computador não apresenta os mecanismos formais de punição e humilhação que os alunos já enfrentaram na escola; ao contrário, a instrução se processa de acordo com o interesse, o ritmo e a forma de organização mental de cada indivíduo.

Usado apropriadamente, $\mathrm{o}$ computador transforma-se numa ajuda imprescindível para a aquisição do conhecimento, possibilitando ao aluno o controle sobre seu desenvolvimento cognitivo e sobre o processo de aprender.

São muitos os receios e as críticas dirigidas ao uso do computador no ensino, considerando-o um instrumento que já nasceu quantitativo e, portanto, limitador da liberdade criativa e autônoma da escrita. Al- 
guns educadores temem a alienação, a dominação, a dependência da tecnologia, a invasão da privacidade e a automatização tomando lugar do humano. Neste projeto pensamos este assunto de forma diferente: ao invés de alienação, acreditamos que o trabalho com computadores nas escolas pode modificar as relações numa sala de aula, de um modelo onde o professor fala e o aluno escuta, para um modelo onde o aluno processa o trabalho junto com o professor, compartilha espontaneamente sua escrita com os colegas, onde algumas formas de controle do professor são deixadas de lado, havendo uma maior aproximação com os alunos e um novo entendimento do processo de aprender. Acreditamos que classes que usam o computador são mais centradas no estudante, pois alunos e professores trabalham juntos.

Além desses aspectos, a habilidade em utilizar computadores tornouse um atributo valioso no mercado de trabalho e nas relações interpessoais, podendo facilitar aos alunos acesso ao mercado de trabalho.

Existem diferentes tipos de softwares instrucionais aplicados à educação, Como são "importados" constituem uma limitação em termos de adequação ao nosso meio e à proposta pedagógica mais atual de ensino da língua materna, com base na lingüística. A utilização desses programas e demais recursos tecnológicos dependerão da habilidade de escolha, de adaptação e de utilização do professor e dos alunos.

\section{Referencial teórico}

O referencial teórico que norteia o projeto apóia-se nos trabalhos desenvolvidos por Paulo Freire e suas ramificações no âmbito da Pedagogia Emancipatória. Como facilitadoras da análise dos processos de aprendizagem, apoiamos-nos nas concepções de Vygotsky sobre "inner speech" e sobre a "re-significação do pensamento". Em Paris e Myers (1981) e em Paris e Oka (1986) encontramos o suporte teórico do sistema de processamento da informação, envolvendo memoria e atenção, em especial os sistemas metacognitivos. Finalmente, em Emilia Ferreiro, o aspecto referente à psicogênese da língua escrita. 
Não nos ateremos, neste projeto, à elaboração da forma como esses aportes teóricos nos auxiliarão, visto que eles serão amplamente explicitados quando da análise dos dados oriundos da pesquisa, que, por sua natureza etnográfica, se constituirá num processo de desvelamento ao longo do desenvolvimento do projeto, não podendo os resultados serem previstos, no momento, de forma hipotética.

\section{Comentários finais}

O Projeto TEIA representa a terceira etapa de um projeto inicial intitulado "Fracasso Escolar: imagens de explicações populares sobre 'dificuldades educacionais' entre jovens de áreas rural e urbana do Estado do Rio de Janeiro". Esse projeto foi desenvolvido numa abordagem etnográfica, caracterizada pela microanálise do contexto, e concluído sob a forma de tese de doutorado de sua coordenadora, em maio de 1992. A segunda etapa do projeto encontra-se em fase de conclusão, e caracteriza-se particularmente pela microanálise crítica da sala de aula, explorando também aspectos da colaboração professor-pesquisador.

Em outubro de 1993, surge a primeira versão do Projeto TEJA, na perspectiva de enfrentar o fracasso escolar de jovens e adultos, especialmente daqueles excluídos do ensino regular, vítimas do processo de injustiça social promovido pela escola. Em constante re-elaboração, assim foi inicialmente pensado, assim será desenvolvido. A abertura a novas idéias é um componente vital para o entendimento e a construção coletiva na educação. Pensando nas contribuições que poderemos receber de colegas e pesquisadores da área, é que estamos abertos a re-pensar nossos objetivos e práticas.

O Projeto TEJA é ambicioso em seu escopo, por tentar abranger simultaneamente ensino, pesquisa e extensão. E ambicioso ainda por envolver tecnologia de computadores numa época em que o Brasil vive uma intensa crise educacional, e por ousar envolver uma clientela marginalizada pelo sistema de ensino formal com alta tecnologia.

Acreditamos que é possível reverter o quadro de marginalização 
social e desperdício de capital humano em um significativo progresso sócio-cultural do jovem, que poderá tornar-se mais autoconfiante e, no futuro, mais produtivo para a sociedade, com grandes possibilidades de recuperação em termos de escolarização formal.

Entendemos que cada indivíduo é uma agência humana e, dentro desta perspectiva, quaisquer esforços da comunidade acadêmica e da sociedade em geral para encaminhar jovens fracassados na escola para o retorno à escolarização é não somente uma obrigação, mas um dever de cada um.

\section{Referências bibliográficas}

BROWN, Ann L. The development of memory: knowing about knowing, and knowing how to know. In: REESE (Ed.). Advances in child development and behavior. New York: Academic Press, 1975.

. Learning how to learn from reading. In: LANGER, J., BUSKE, M. Smith (Eds.). Reader meeis auíhor bridging the gap: a Psycholinguistic and sociolinguistic perspective. IRA, 1982.

BRUNNER, Cornelia. Designing inquire. [S.1.]: Center for Children: Technology Bank Street Collège of Education, 1990. (Tecnical report, 50).

BURENSTAIN, B.D. Computer in the language arts. [S.1.]: Drexel University, 1986.

FERREIRO, E. Reflexões sobre a alfabetização. São Paulo: Cortez, 1985.

FERRREIRO, E., TEBEROSKY, A Psicogênese da língua escrita. Porto Alegre: Artes Médicas, 1986.

FREIRE, Paulo. The adult literacy process as cultural action for freedom. Harvard Educational Review, v.40, n.2, p.205-225, 1970.

Literacy and the possible dream. Prospect, v.6, n.1, p.68-71, 1976. 
. The people speak their

word: learning to read and write in São Tome and Príncipe. Harvard Educational Review, v.51, n.1, p.27-30, 1981.

HONNEY, M., MOELLER, B., BRUN- NER, C. et al. Girls $e$ designer: exploring the question of techological imagination. [S.1.]: Bank Street Collège of Education, 1991.

MATTOS, C.L.G. Piciuring school failure: a study of diversity in explanations of "educational difficulties" among rural and urban youth in Brazil. Philadelphia, 1992. Tese (Doutorado em Filosofia da Educação) - University of Pennsylvania.

MATTOS, C.L.G. de. Cross-natio nal studies of learning: picluring school failure: a study of diversity in explanations of "educational difficulties" among rural and urban youth in Brazil. Paper presented at the Fourteenth Annual University of Pennsylvania Ethnography in Education Research Fórum, 1993.
MATTOS, C.L.G. de. Fracasso escolar: as explicações face a face. $R e$ vista do Mackenzie, v.l, n.9,1994.

MATTOS, C.L.G., BURENSTAIN, B. D. Computer in education. Philadelphia University of Pennsylvania, 1986.

MATTOS, C.L.G. et al. Fracasso escolar:imagens de explicações populares sobre "dificuldades educacionais" entre jovens de áreas rurais e urbanas no Estado do Rio de Janeiro. Revista Brasileira de Estudos Pedagógicos, Brasília, v.73, n.174, p.368377, maio/ago. 1992.

PARIS, S.G., MAYERS. Compre hension monitoring, memory and study Strategies of good and poor readers. Journal of Reading Behavior, n.13, p.5-22, 1981.

PARIS, S.G., OKA, E.R. Childrens reading Strategies: metacognition and motivation. Developmental Review, n.6, p.25-66, 1986.

PATTO, M.H.S. A reprodução do fracasso escolar: histórias de 
submissão e rebeldia. São Paulo: T.A. Queiroz, 1991.

STREET, Brian V. Literacy in theory and practice. Cambridge:
Cambridge University Press, 1984.

VYGOTSKY, LS. Pensamento e linguagem. Lisboa: Antídoto, 1979. 